\title{
Planetarium Virtual Sebagai Media Pembelajaran Astronomi Berbasis Virtual Reality
}

\author{
Danang Aji Pangestu ${ }^{\mathrm{a} 1}$, Iskandar Fitria ${ }^{\mathrm{a} 2}$, Fauziah ${ }^{\mathrm{a} 3}$ \\ ${ }^{a}$ Informatika, Fakultas Teknologi Komunikasi dan Informatika, Universitas Nasional \\ Jl. Sawo Manila, RT.14/RW.3, Ps. Minggu, Kec. Ps. Minggu, Kota Jakarta Selatan, Daerah Khusus Ibukota Jakarta \\ ${ }^{1}$ nangjipangegmail.com \\ 2iskandar.fitri@civitas.unas.ac.id \\ ${ }^{3}$ fauziahecivitas.unas.ac.id
}

\begin{abstract}
Abstrak
Dunia digital sangat cocok digunakan sebagai media pembelajaran, salah satunya sebagai media pembelajaran atau edukasi mengenai astronomi tata surya. Pengenalan terkait sistem tata surya dapat memanfaatkan media digital, menurut peneliti dikarenakan seseorang akan lebih menangkap media pembelajaran dengan cara visual secara 3D dibandingkan dengan cara pembelajaran menggunakan media 2D. Salah satu media pembelajaran 3D dapat memanfaatkan teknologi Virtual Reality. Untuk itu penelitian ini menghadirkan plan etarium dengan cara virtual yang dapat menjadi media pembelajaran dengan memanfaatkan teknologi Virtual Reality. Pengembangan pada sistem ini menggunakan model ADDIE Analysis (Analisis), Design (Desain), Develop (Pengembangan), Implement (Implementasi), Evaluate (Evaluasi). Dengan adanya aplikasi Planetarium Virtual membuat seseorang dapat menjelajah seolah-olah dalam planetarium dan didesain menyerupai ruang angkasa. Hasil pengujian dilakukan dengan angka skala 1 sampai dengan 5 yang dilakukan 119 responden, Berdasarkan hasil pengujian yang dilakukan terhadap 119 responden melalui kuesioner, menunjukkan tingkat kepuasan pengguna aplikasi terhadap interface (tampilan) aplikasi tersebut yaitu sebesar 18,5\% untuk skala 3, 53,8\% untuk skala 4, dan $27,7 \%$ untuk skala 5 . Kemudian hasil yang didapat untuk tingkat kepuasan terhadap fungsi atau kegunaan aplikasi oleh pengguna yaitu $22,7 \%$ untuk skala 3, 47,9\% untuk skala 4 , dan 29,4\% untuk skala 5. Aplikasi dapat dioprasikan pada sistem operasi android minimal versi KitKat.
\end{abstract}

Kata kunci: Virtual Reality, Edukasi, ADDIE Models, Planetarium, Objek 3D

\section{Virtual Planetarium as Astronomy a Learning Media Based on Virtual Reality}

\begin{abstract}
The digital world is very suitable to be used as a medium of learning, one of which is as a medium of learning or education about solar system astronomy. research related to the solar system can utilize digital media, according to researchers because someone will better capture learning media in a 3D visual way compared to learning using 2D media. One of the 3D learning media can utilize Virtual Reality technology. For this reason, this research presents a planetarium in a virtual way that can become a learning medium by utilizing Virtual Reality technology. Development in this system uses the ADDIE Analysis, Design, Develop, Implement, Evaluate model. With the Virtual Planetarium application, one can explore as if in a planetarium and is designed to resemble space. The test results were carried out with a scale of numbers 1 to 5 conducted by 119 respondents. $8 \%$ for scale 4 , and $27.7 \%$ for scale 5 . Then the results obtained for the level of satisfaction with the function or usability of the application by the user are $22.7 \%$ for scale $3,47.9 \%$ for scale 4 , and $29.4 \%$ for a scale of 5 . Applications can be operated on the Android operating system at least the KitKat version.
\end{abstract}

Keywords: Virtual Reality, Education, ADDIE Models, Planetarium, 3D Object

\section{Pendahuluan}

Planetarium merupakan sarana atau tempat pembelajaran terkait dunia astronomi luar angkasa yang didalamnya terdapat miniatur, simulasi, dan penjelasan sebagai media edukasi. Terkadang kita harus berkunjung ketempat planetarium untuk menambah wawasan. Dan tidak semua kota terdapat objek wisata planetarium. Untuk itu peran teknologi virtual reality dibutuhkan sebagai media pembelajaran.

Penelitian menggunakan model ADDIE pada penelitian terdahulu, dilakukan penelitian Pengembangan Virtual 
Reality Pengenalan Binatang Buas Untuk Anak Usia Dini (Studi Kasus: TK Negeri Pembina Singaraja) dimana menampilkan binatang buas secara virtual [1]. Pada penelitian lain menggunakan model ADDIE pada Game Edukasi "Penjajah" Barbasis Virtual Reality yang digunakan sebagai mengenali dan mempelajari bendabenda prasejarah di Indonesia [2]. Penelitian terkait juga dilakukan pada penelitian Rancangan Game Balinese Fruit Shooter Berbasis Virtual Reality Sebagai Media Pembelajaran, dimana menggunakan Virtual Reality sebagai bahan pengenalan buah lokal bali dalam bentuk game [3]. Teknologi Virtual Reality juga dilakakukan pada Pemanfaatan Teknologi 3D Virtual Reality Pada Pembelajaran Matematika Tingkat Sekolah Dasar yang didesain berupa labirin dan terdapat soal-soal matematika dasar didalamnya [4].

Pemanfaatan Virtual Reality pada media edukasi juga dilakukan pada Aplikasi Berbasis Virtual Reality Untuk Mendukung Proses Pembelajaran Organ Pencernaan Manusia yang digunakan sebagai pembelajaran yang menarik dan dianggap efektif [5]. Penelian lainnya juga dilakukan pada Virtual Reality For Learning Fish Types In Kindergarten dimana teknologi Virtual Reality dimanfaatkan sebagai media pengenalan 10 jenis ikan tawar, dan 10 jenis ikan asin pada siswa Taman KanakKanak [6].

Berdasarkan beberapa penelitian terdahulu model ADDIE sudah banyak digunakan sebagai media pembelajaran berbasis Virtual Reality. Untuk itu penelitian ini, penulis memanfaatkan teknologi Virtual Reality sebagai media edukasi yang didalamnya terdapat pergerakan tata surya, dan penjelasan mengenai planetplanet yang ada.

\section{Metode PENELITIAN}

Pada pembuatan aplikasi planetarium virtual, digunakan model pengembangan software ADDIE yang terdiri dari 5 tahapan penelitian. Tahapan-tahapan penlelitian yaitu Analysis (Analisis), Design (Desain), Develop (Pengembangan), Implement (Implementasi), Evaluate (Evaluasi).

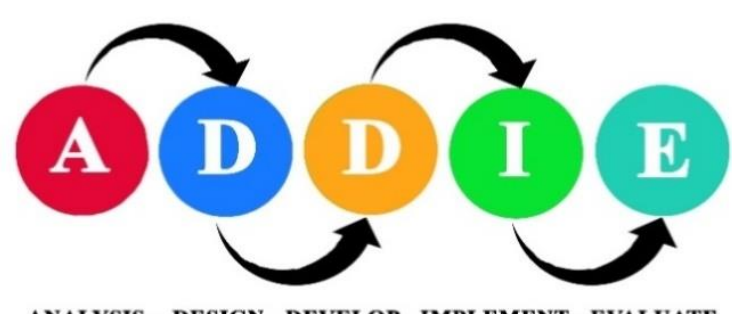

Gambar 1. ADDIE Model

Berikut merupakan rancangan tahapan pembuatan aplikasi Plenetarium Virtual menggunakan Addie Models (Gambar 1):

\section{Analysis (Analisis)}

Tahap pertama merupakan perancangan pengumpulan berupa analisa yang dibutuhkan dalam aplikasi Planetarium Virtual. Pengumpulan data yang dibutuhkan seperti nama-nama planet yang ada ditata surya dan perpututaran planet mengelilingi matahari. Pada aplikasi Planetarium Virtual, pengguna dapat berinteraksi seolaholah sedang berada dalam ruangan yang dirancang seperti ruang angkasa.

\section{Design (Desain)}

Pada tahap ini dilakukan perancangan desain pada aplikasi yang sudah dianalisis pada tahap analysis atau tahap pertama. Pembuatan desain meliputi perancangan 3D digunakan untuk mendesain media virtual yang terdiri dari desain ruangan planetarium, pembuatan planet-planet yang terdapat pada tata surya, dan pengaturan cahaya pada ruangan tersebut.

\section{Develop (Pengembangan)}

Tahap pengembangan yaitu menyusun semua persiapan yang telah didesain, dan disusun menjadi sebuah kerangka game. Penyusunan kerangka meliputi memasukan assetasset yang didesain kedalam game engine Unity, memasukan Cardboard SDK, dan menyusun layout ruangan.

\section{Implement (Implementasi)}

Tahap impementasi merupakan tahap dimana aplikasi siap untuk dilakukan pengujian. Pengujian memastikan aplikasi menghasilkan output yang sesuai dari tahap-tahap sebelumnya yang sudah dirancang, meminimalisir kesalahan, memastikan tidak ada error, dan memastikan tidak adanya bug pada aplikasi.

\section{Evaluate (Evaluasi)}

Yang terakhir yaitu melakukan evaluasi aplikasi. Evaluasi dilakukan dengan cara uji respon pengguna dari aplikasi Planetarium Virtual sebagai pengukuran tingkat keberhasilan.

\section{A. Use Case Diagram}

Use Case Diagram merupakan sebuah teknik yang digunakan dalam pengembangan sebuah software atau sistem informasi untuk menangkap kebutuhan fungsional dari sistem yang bersangkutan [2].

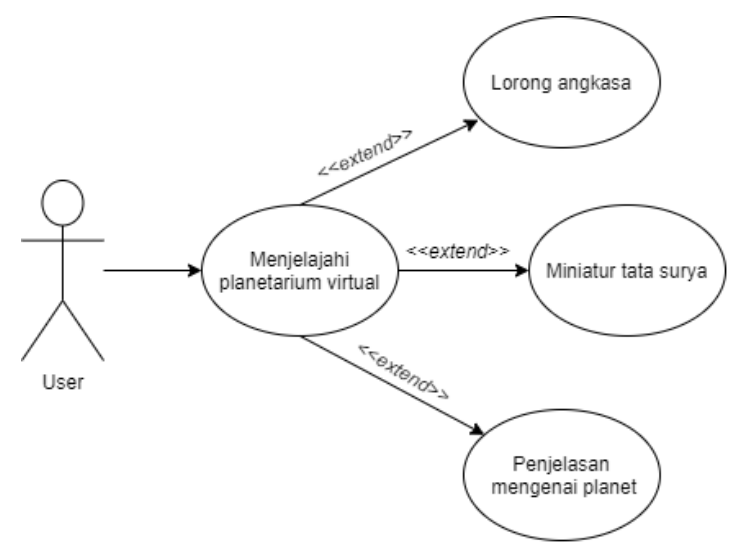

Gambar 2. Use Case Diagram Planetarium Virtual

\section{B. Kebutuhan Sistem}

Demi mendukung kebutuhan sebagai penunjang pembuatan aplikasi Planetarium Virtual, tentunya memerlukan perangkat yang memadai, baik dari sisi software (perangkat lunak) dan juga hardware (perangkat keras). Untuk itu perlu adanya dukungan pada perangkat 
hardware dan software. Kebutuhan sistem dapat dilihat pada tabel 1 dan tabel 2 .

TABEL I

SPESIFIKASI PERANGKat KeRAS YANG DigunaKan DALAM PEMBUATAN APLIKASI

\begin{tabular}{|l|l|l|}
\hline No. & Perangkat & Spesifikasi \\
\hline 1 & Processor & $\begin{array}{l}\text { Intel } ₫ \text { Core } \\
@ 3.20 \mathrm{GHz} \text { (4 CPUs). } 440 \mathrm{CPU}\end{array}$ \\
\hline 2 & RAM & $8 \mathrm{~GB}$ \\
\hline 3 & Harddisk & $500 \mathrm{~GB}$. \\
\hline
\end{tabular}

TABEL III

SPESIFIKASI PERANGKat LUNAK Yang DigunaKan Dalam PEMBUATAN APLIKASI

\begin{tabular}{|l|l|l|}
\hline No. & Perangkat & Kegunaan \\
\hline 1 & $\begin{array}{l}\text { Sistem Operasi Microsoft } \\
\text { Windows 7 Professional } \\
\text { 64-bit }\end{array}$ & $\begin{array}{l}\text { Sistem operasi yang } \\
\text { digunakan peneliti dalam } \\
\text { membangun aplikasi. }\end{array}$ \\
\hline 2 & $\begin{array}{l}\text { Unity 3D 2017.3.0f3 64- } \\
\text { bit }\end{array}$ & $\begin{array}{l}\text { Merupakan game engine } \\
\text { berbasis 3D yang digunakan } \\
\text { untuk pembuatan Virtual } \\
\text { Reality.Selain disistem } \\
\text { operasi windows, software } \\
\text { unity dapat dijalankan pada } \\
\text { sistem operasi lain seperti } \\
\text { linux dan mac os. }\end{array}$ \\
\hline 3 & Google Cardboard SDK & $\begin{array}{l}\text { Sebagai SDK (Software } \\
\text { Development Kit) dalam } \\
\text { pembangunan aplikasi } \\
\text { Virtual reaality agar dapat } \\
\text { membaca objek pada } \\
\text { perangkat mobile pada game } \\
\text { engine Unity. }\end{array}$ \\
\hline 4 & $\begin{array}{l}\text { Adobe Photoshop CS6 } \\
\text { (64-bit) }\end{array}$ & $\begin{array}{l}\text { Media pembuatan desain 2D } \\
\text { sebelum dimasukan kedalam } \\
\text { unity. }\end{array}$ \\
\hline 5 & $\begin{array}{l}\text { Microsoft Visual Studio } \\
\text { 2017 }\end{array}$ & $\begin{array}{l}\text { Pembuatan source code pada } \\
\text { aplikasi Planetarium Virtual } \\
\text { menggunakan bahasa } \\
\text { pemrograman C\#. }\end{array}$ \\
\hline 6 & Draw.io & $\begin{array}{l}\text { Pembuatan diagram alir } \\
\text { tentang kegunaan dan cara } \\
\text { kerja dari aplikasi. }\end{array}$ \\
\hline & &
\end{tabular}

\section{HASIL DAN PEMBAHASAN}

A. Impementasi GUI (Graphic User Interface) saat Planetarium Virtual dimainkan.

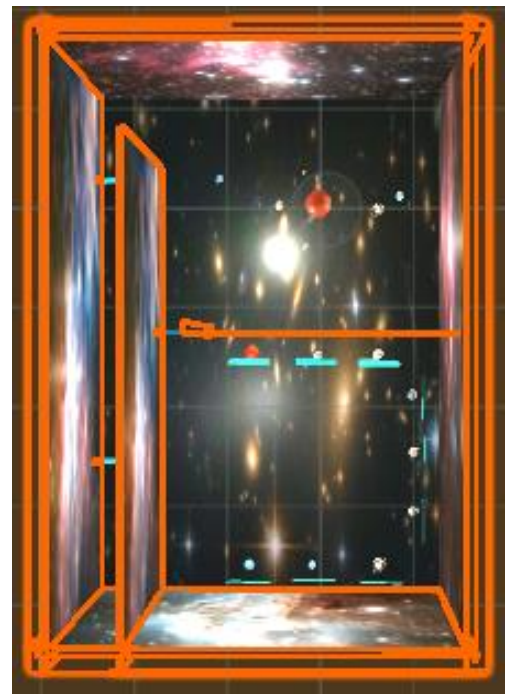

Gambar 3. Tampilan Desain Ruangan Didalam Aplikasi Planetarium Virtual

Desain tampilan Virtual Reality pada aplikasi Planetarium Virtual terdiri dari 3 ruangan. Ruangan tersebut antara lain lorong angkasa, ruang simulasi tata surya, dan ruang penjelasan tentang planet. Berikut merupakan desain ruangan pada saat dimainkan dapat dilihat pada storyboard tabel 3 .

TABEL IIIII

STORYBOARD RUANGAN-RUANGAN YANG ADA PADA APLIKASI PLANETARIUM VIRTUAL

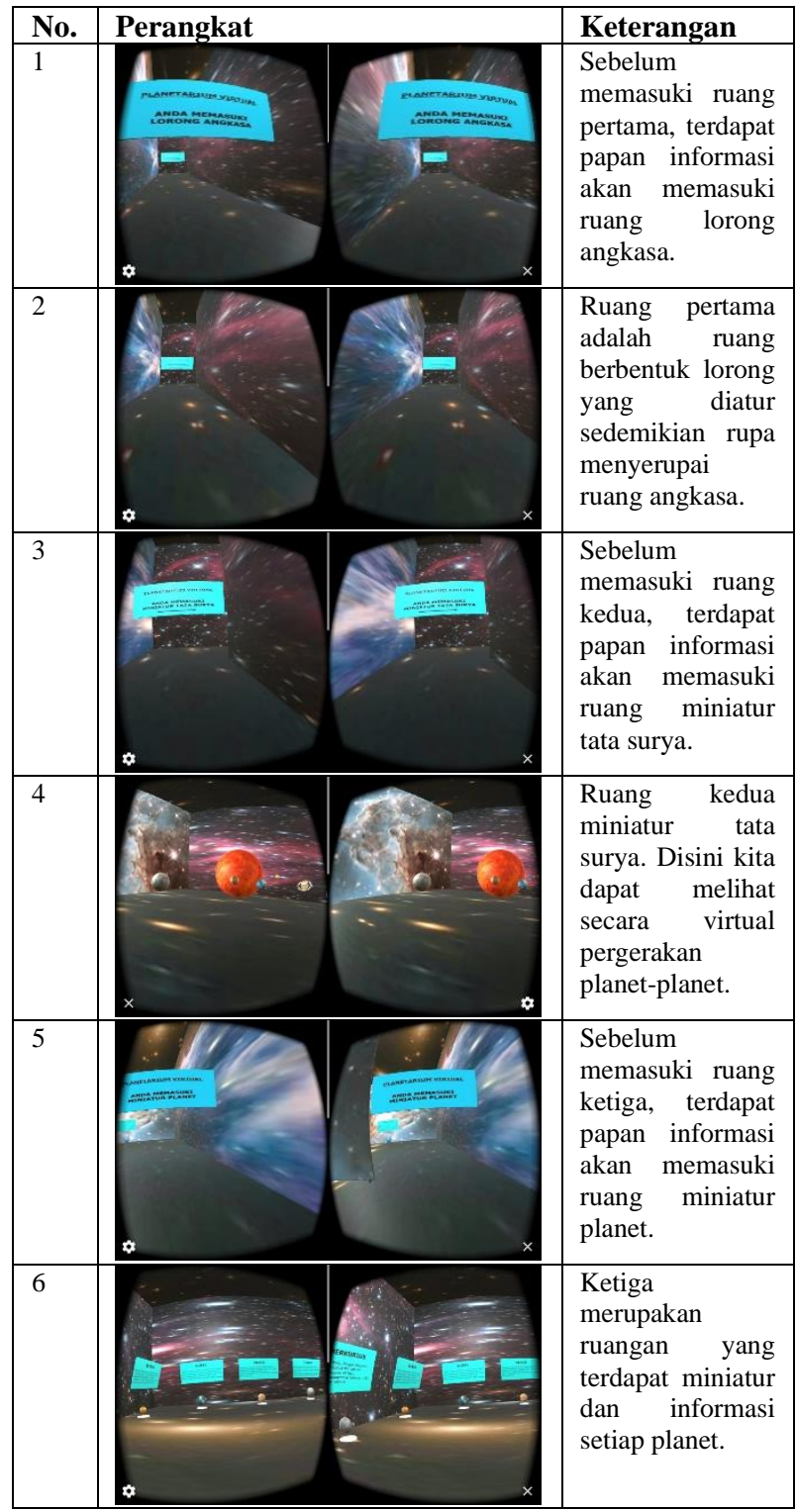

B. Pengujian Aplikasi Pada Perangkat Yang Berbeda

Pada aplikasi Planetarium Virtual dilakukan beberapa pengujian, antara lain dari sisi versi android, display (tampilan), Processor dan RAM. Hal tersebut mempengaruhi perangkat untuk dapat diinstal atau tidak, tampilan, dan respon pergerakan pada tiap-tiap device.

Pengujian dilakukan dengan menggunakan 8 buah perangkat smartphone android dengan versi android yang berbeda-beda. Dari 8 perangkat yang dilakukan untuk 
pengujian, hanya terdapat 7 perangkat yang dapat menjankan Aplikasi Virtual Reality. Berikut merupakan daftar smartphone yang dilakukan untuk pengujian yang tersedia pada tabel 4 , tabel 5 dan tabel 6 .

TABEL IVV

Perangkat Yang Pada Digunakan Untuk Pengujian

\begin{tabular}{|l|l|l|l|}
\hline No. & Perangkat & Versi Android & Status \\
\hline 1 & $\begin{array}{l}\text { Smartfren } \\
\text { Andromax C }\end{array}$ & 4.1 (JelyBean) & $\begin{array}{l}\text { Tidak Dapat } \\
\text { Dijalankan }\end{array}$ \\
\hline 2 & $\begin{array}{l}\text { Smartfren } \\
\text { Andromax C3 }\end{array}$ & 4.4 .2 (Kitkat) & $\begin{array}{l}\text { Dapat } \\
\text { Dijalankan }\end{array}$ \\
\hline 3 & Oppo a37f & 5.1 (Lolipop) & $\begin{array}{l}\text { Dapat } \\
\text { Dijalankan }\end{array}$ \\
\hline 4 & Nubia M2 & 6.0 (Marshmallow) & $\begin{array}{l}\text { Dapat } \\
\text { Dijalankan }\end{array}$ \\
\hline 5 & Vivo Y95 & 7.1 (Nougat) & $\begin{array}{l}\text { Dapat } \\
\text { Dijalankan }\end{array}$ \\
\hline 6 & Oppo A3s & $8.1($ Oreo) & $\begin{array}{l}\text { Dapat } \\
\text { Dijalankan }\end{array}$ \\
\hline 7 & $\begin{array}{l}\text { Asus Zenfone } \\
\text { Max Pro M2 }\end{array}$ & 9.0 (Pie) & $\begin{array}{l}\text { Dapat } \\
\text { Dijalankan }\end{array}$ \\
\hline 8 & Samsung M20 & $10.0(\mathrm{Q})$ & $\begin{array}{l}\text { Dapat } \\
\text { Dijalankan }\end{array}$ \\
\hline
\end{tabular}

TABEL V

SPESIFIKASI DISPLAY PADA PERANGKAT YANG DIGUNAKAN UNTUK PENGUJIAN

\begin{tabular}{|c|c|c|}
\hline No. & Perangkat & Display \\
\hline 1 & Smartfren Andromax C & $\begin{array}{l}\text { IPS LCD capacitive } \\
\text { touchscreen, 16M colors, } \\
4.0 \text { inches, Resolutiom } \\
\text { WVGA; Capacitive Multi } \\
\text { Touch Screen with Multi } \\
\text { Gesture }\end{array}$ \\
\hline 2 & Smartfren Andromax C3 & $\begin{array}{l}\text { IPS LCD capacitive } \\
\text { touchscreen, 16M colors, } \\
4.0 \text { inches, Resolutiom } \\
\text { WVGA; Capacitive Multi } \\
\text { Touch Screen with Multi } \\
\text { Gesture }\end{array}$ \\
\hline 3 & Oppo a37f & $\begin{array}{l}\text { IPS LCD } \text { capacitive } \\
\text { touchscreen, } 16 \mathrm{M} \text { colors, } \\
5.0 \text { inches, } 68.9 \\
\mathrm{~cm}^{2}(\sim 67.8 \% \text { screen-to- } \\
\text { body ratio), } 720 \times 1280 \\
\text { pixels, 16:9 ratio }(\sim 294 \\
\text { ppi density) }\end{array}$ \\
\hline 4 & Nubia M2 & $\begin{array}{l}\text { AMOLED capacitive } \\
\text { touchscreen, } 16 \mathrm{M} \text { colors, } \\
5.5 \text { inches, } 83.4 \\
\mathrm{~cm}^{2}(\sim 71.1 \% \text { screen-to- } \\
\text { body ratio), } 1080 \times 1920 \\
\text { pixels, 16:9 ratio }(\sim 401 \\
\text { ppi density) }\end{array}$ \\
\hline 5 & Vivo Y95 & $\begin{array}{l}\text { IPS LCD } \text { capacitive } \\
\text { touchscreen, } 16 \mathrm{M} \text { colors, } \\
6.22 \text { inches, } 96.6 \\
\mathrm{~cm}^{2}(\sim 82.9 \% \text { screen-to- } \\
\text { body ratio), } 720 \times 1520 \\
\text { pixels, } 19: 9 \text { ratio }(\sim 270 \\
\text { ppi density) }\end{array}$ \\
\hline 6 & Oppo A3s & $\begin{array}{l}\text { IPS LCD capacitive } \\
\text { touchscreen, } 16 \mathrm{M} \text { colors, } \\
6.2 \text { inches, } 95.9 \\
\mathrm{~cm}^{2}(\sim 81.2 \% \text { screen-to- } \\
\text { body ratio), } 720 \times 1520 \\
\text { pixels, } 19: 9 \text { ratio }(\sim 271 \\
\text { ppi density) }\end{array}$ \\
\hline 7 & Asus Zenfone Max Pro M2 & $\begin{array}{l}\text { IPS LCD capacitive } \\
\text { touchscreen, } 16 \mathrm{M} \text { colors, }\end{array}$ \\
\hline
\end{tabular}

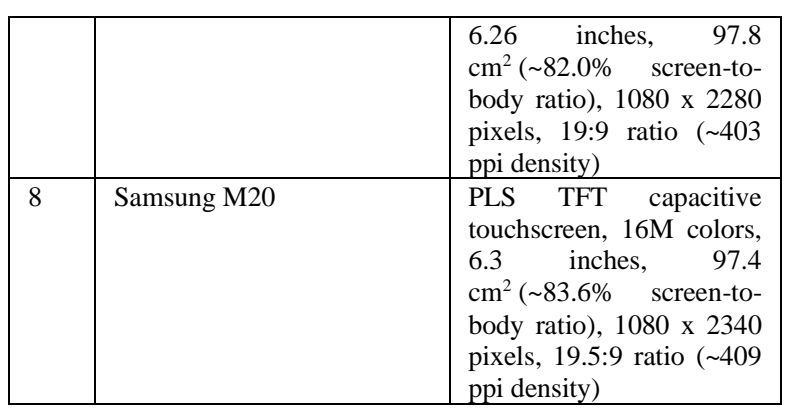

TABEL VI

SPESIFIKASI PROCESSOR DAN RAM PADA PERANGKAT YANG DIGUNAKAN UNTUK PENGUJIAN

\begin{tabular}{|c|c|c|}
\hline No. & Perangkat & Versi Android \\
\hline 1 & Smartfren Andromax C & $\begin{array}{l}\text { Qualcomm MSM8625 Dual } \\
\text { Core 1GHz ARMv7, GPU: } \\
\text { Adreno 203, Memory RAM } \\
\text { 512MB }\end{array}$ \\
\hline 2 & Smartfren Andromax C3 & $\begin{array}{lrr}\text { Snapdragon Dual } & \text { Core } \\
1.2 \mathrm{GHz}, \text { Memory } & \text { RAM } \\
512 \mathrm{MB} & & \\
\end{array}$ \\
\hline 3 & Oppo a37f & $\begin{array}{l}\text { Quad-core } 1.2 \mathrm{GHz} \text { Cortex- } \\
\text { A53, Memory RAM 2GB }\end{array}$ \\
\hline 4 & Nubia M2 & $\begin{array}{l}\text { Octa-core } 2.0 \mathrm{GHz} \text { Cortex- } \\
\text { A53, Memory RAM 4GB }\end{array}$ \\
\hline 5 & Vivo Y95 & $\begin{array}{l}\text { Octa-core }(4 \times 1.95 \mathrm{GHz} \\
\text { Cortex-A53 \& 4x1.45 GHz } \\
\text { Cortex A53), Memory } \\
\text { RAM 4GB }\end{array}$ \\
\hline 6 & Oppo A3s & $\begin{array}{l}\text { Octa-core } 1.8 \mathrm{GHz} \text { Cortex- } \\
\text { A53, Memory RAM 4GB }\end{array}$ \\
\hline 7 & $\begin{array}{l}\text { Asus Zenfone Max Pro } \\
\text { M2 }\end{array}$ & $\begin{array}{l}\text { Octa-core (4x2.2 GHz Kryo } \\
260 \text { Gold \& 4x1.8 GHz } \\
\text { Kryo } 260 \text { Silver), Memory } \\
\text { RAM 4GB }\end{array}$ \\
\hline 8 & Samsung M20 & $\begin{array}{llr}\text { Octa-core } & (2 \times 1.8 & \mathrm{GHz} \\
\text { Cortex-A73 } & \& & 6 \times 1.6 \mathrm{GHz} \\
\text { Cortex-A53), } & \text { Memory } \\
\text { RAM 4GB } & & \\
\end{array}$ \\
\hline
\end{tabular}

\section{Pengujian Respon Aplikasi Pada Perangkat}

Pengujian Respon Aplikasi Pada Perangkat Perangkat smartphone yang memiliki sensor Gyroscope, membuat pengguna soalah-olah dapat berjalan pada aplikasi Virtual Reality, meski demikian masih membutuhkan waktu yang sedikit lama. Berikut merupakan daftar respon dari masing-masing perangkat smartphone yang dilakukan untuk pengujian yang tersedia pada tabel 7 .

TABEL VII

KECEPATAN RESPON PERANGKAT

\begin{tabular}{|l|l|l|c|}
\hline No. & Perangkat & Versi Android & Respon \\
\hline 1 & $\begin{array}{l}\text { Smartfren } \\
\text { Andromax C }\end{array}$ & 4.1 (JelyBean) & - \\
\hline 2 & $\begin{array}{l}\text { Smartfren } \\
\text { Andromax C3 }\end{array}$ & 4.4 .2 (Kitkat) & 4 detik \\
\hline 3 & Oppo a37f & 5.1 (Lolipop) & 3,2 detik \\
\hline 4 & Nubia M2 & 6.0 (Marshmallow) & 2,7 detik \\
\hline 5 & Vivo 1807 & 7.1 (Nougat) & 2,7 detik \\
\hline 6 & Oppo A3s & 8.1 (Oreo) & 2,4 detik \\
\hline 7 & $\begin{array}{l}\text { Asus Zenfone } \\
\text { Max Pro M2 }\end{array}$ & 9.0 (Pie) & 2 detik \\
\hline 8 & Samsung M20 & $10.0(\mathrm{Q})$ & 2 detik \\
\hline
\end{tabular}




\section{Kuesioner Responden}

Kuesioner dilakukan oleh 119 orang responden. Berdasarkan data yang diberikan oleh responden melalui pengisian kuesioner. Penilaian dilakukan menggunakan nilai skor dengan skala angka 1 sampai dengan 5 .

Berdasarkan hasil pengujian yang dilakukan terhadap 119 responden melalui kuesioner, menunjukkan menunjukkan tingkat kepuasan pengguna aplikasi terhadap interface (tampilan) aplikasi tersebut yaitu sebesar $18,5 \%$ untuk skala $3,53,8 \%$ untuk skala 4 , dan $27,7 \%$ untuk skala 5 .

Kemudian hasil yang didapat untuk tingkat kepuasan terhadap fungsi atau kegunaan aplikasi oleh pengguna yaitu $22,7 \%$ untuk skala 3, 47,9\% untuk skala 4, dan 29,4\% untuk skala 5. Dengan nilai tersebut, maka aplikasi Planetarium ini dapat dinilai sukses dan berhasil.

\section{KESIMPULAN}

Berdasarkan uraian penelitian, untuk itu dapat disimpulkan yang diuraikan menjadi beberapa poin, antara lain:

Aplikasi Planetarium Virtual dibuat dengan tujuan memberi edukasi tentang sistem tata surya yang dirancang dalam bentuk 3D menggunakan teknologi Virtual Reality, dimana pengguna dapat seolah-olah berada pada planetarium yang didesain menyerupai ruang angkasa..

Aplikasi dapat dijalankan pada android dengan operasi android minimal operasi sistem yaitu KitKat dan disarankan menjalankan dengan minimal RAM 4GB.

Berdasarkan hasil responden dengan skala 1 sampai dengan 5 menujukan tingkat kepuasan penggunaan aplikasi tersebut yaitu skala 3 sebesar $18,5 \%$, skala 4 sebesar $53,8 \%$, skala 5 sebesar $27,7 \%$ dari sisi interface (tampilan).

Dan hasil responden dengan skala 1 sampai dengan 5 pada sisi fungsi atau kegunaan menunjukan skala 3 sebesar $22,7 \%$, skala 4 sebesar $47,9 \%$, skala 5 sebesar 29,4\%. Dapat disimpulkan aplikasi tersebut telah sukses dan berhasil

\section{DAFTAR PUSTAKA}

[1] I. M. A. Pradnyana, I. K. R. Arthana, and I. G. B. H. Sastrawan, "Pengembangan Virtual Reality Pengenalan Binatang Buas Untuk Anak Usia Dini ( Studi Kasus: TK Negeri Pembina Singaraja )," Lontar Komput., vol. 8, no. 3, pp. 188-199, 2017.

[2] R. W. K. I. M. P. S. T. M. T., and . D. K. A. S. S. M. S "Game Edukasi Penjelajah Berbasis Virtual Reality," Kumpul. Artik. Mhs. Pendidik. Tek. Inform., vol. 7, no. 1, p. 20, 2018, doi: 10.23887/karmapati.v7i1.13592.

[3] R. Sistem, G. Y. Wiryawan, D. Gede, H. Divayana, and G. A. Pradnyana, "JURNAL RESTI," vol. 1, no. 10, 2021.

[4] K. Dwipayana, I. M. A. Wirawan, and I. G. P. Sindu, "Go-Byar Based on Virtual Reality for the Learning Media of Gamelan," vol. 25, no. 2, pp. 229-236, 2019, doi: 10.21831/jptk.v25i2.26182.

[5] R. K. Dewi, "Pemanafaatan Media 3 Dimensi Berbasis Virtua Reality Untuk Meningkatkan Minat Dan Hasil Belajar Ipa Siswa Kelas V Sd," J. Pendidik., vol. 21, no. 1, pp. 28-37, 2020, doi 10.33830/jp.v21i1.732.2020.

[6] D. Kamińska et al., "Virtual reality and its applications in education: Survey," Inf., vol. 10, no. 10, pp. 1-20, 2019, doi: 10.3390/info10100318.

[7] D. L. Gunawan, Liliana, and G. S. Budhi, "Pembuatan Kebun Binatang Virtual Untuk Pembelajaran Mengenai Binatang Liar," p. $6,2016$.
[8] E. A. Alrehaili and H. Al Osman, "A virtual reality role-playing serious game for experiential learning," Interact. Learn. Environ., vol. $0, \quad$ no. $0, \quad$ pp. 1-14, 2019, doi: 10.1080/10494820.2019.1703008

[9] C. Y. Chang, H. Y. Sung, J. L. Guo, B. Y. Chang, and F. R. Kuo, "Effects of spherical video-based virtual reality on nursing students' learning performance in childbirth education training," Interact. Learn. Environ., vol. 0, no. 0, pp. 1-17, 2019, doi: 10.1080/10494820.2019.1661854.

[10] F. Y. Chiu, "Virtual reality for learning languages based on mobile devices," 2017 16th Int. Conf. Inf. Technol. Based High. Educ. Training, ITHET 2017, pp. 5-7, 2017, doi: 10.1109/ITHET.2017.8067813.

[11] G. T. A. Kusuma, I. M. A. Wirawan, and I. K. R. Arthana, "Virtual reality for learning fish types in kindergarten," Int. J. Interact. Mob. Technol., vol. 12, no. 8, pp. 41-51, 2018, doi: 10.3991/ijim.v12i8.9246.

[12] B. I. Edwards, K. S. Bielawski, R. Prada, and A. D. Cheok, "Haptic virtual reality and immersive learning for enhanced organic chemistry instruction," Virtual Real., vol. 23, no. 4, pp. 363-373, 2019, doi: 10.1007/s10055-018-0345-4.

[13] M. Syafi, "Aplikasi Berbasis Virtual Reality untuk Mendukung Proses Pembelajaran Organ Pencernaan Manusia Virtual Reality Based Application to Support Learning Process of Human Digestive Organs," 2012.

[14] A. Rachman, J. S. Informasi, F. T. Informasi, J. T. Informatika, and F. T. Informasi, "Pemanfaatan Teknologi 3D Virtual Reality Pada," J. Ilm., vol. 3, no. 1, pp. 37-44, 2017.

[15] M. A. Pranata, G. S. Santyadiputra, and I. G. P. Sindu, "Rancangan Game Balinese Fruit Shooter Berbasis Virtual Reality Sebagai Media Pembelajaran,"J. Nas. Pendidik. Tek. Inform., vol. 6, no. 3, p. 256, 2018, doi: 10.23887/janapati.v6i3.11994.. 